\title{
Necessitism, Contingentism, and Lewisian Modal Realism
}

\author{
Cristina Nencha ${ }^{1}$ (1)
}

Received: 13 October 2020 / Accepted: 21 June 2021 /Published online: 5 August 2021

(c) The Author(s) 2021

\begin{abstract}
Necessitism is the controversial thesis that necessarily everything is necessarily something, namely that everything, everywhere, necessarily exists. What is controversial about necessitism is that, at its core, it claims that things could not have failed to exist, while we have a pre-theoretical intuition that not everything necessarily exists. Contingentism, in accordance with common sense, denies necessitism: it claims that some things could have failed to exist. Timothy Williamson is a necessitist and claims that David Lewis is a necessitist too. The paper argues that, granted the assumptions that lead to interpret the Lewisian as a necessitist, she can preserve contingentist intuitions, by genuinely agreeing with the folk that existence is contingent. This is not just the uncontroversial claim that the Lewisian, as a result of the prevalence of restricted quantification in counterpart theoretic regimentations of natural language, can agree with the folk while disagreeing with them in the metaphysical room. Rather, this is the claim that it is in the metaphysical room that the Lewisian can endorse the intuitions lying behind contingentism.
\end{abstract}

Keywords Necessitism · Contingentism · David Lewis · Counterpart theory · Unrestricted quantification

\section{Introduction}

Necessitism is the thesis that necessarily everything is necessarily something, that is, that everything everywhere necessarily exists. I take necessitism to be a strongly counter-intuitive thesis. What is counter-intuitive about necessitism is that, while we have a pre-theoretical intuition that things could have failed to exist, necessitism claims that it is necessary what there is, namely that the ontology is necessary. The negation of necessitism is contingentism, which holds that the ontology is contingent, namely, that it is contingent what there is. Hence, contingentists, in accordance

Cristina Nencha

cristina.nencha@libero.it

1 Dipartimento Di Studi Umanistici, Università Degli Studi Di Napoli Federico II, Via Porta di massa, 1, 80133 Naples, Italy 
with common sense, believe that there are, or there could be, things that could have failed to exist (Williamson, 2013: 1-3).

Timothy Williamson (2013: 17) is a necessitist and claims that David Lewis is a necessitist too. John Divers (2014b: 728) agrees with Williamson's interpretation of Lewis. However, this seems surprising. In Phillip Bricker's words: "That would have been news to Lewis, who certainly took himself to be a contingentist" (2014: 723). Indeed, as we saw, necessitism implies invariably necessary existence, but, according to the Lewisian version of counterpart theoretic interpretation (1968), claims of necessary existence are not invariably true. Indeed, it is sufficient for the contingent existence of an individual that there should be some possible worlds in which it has no counterparts, and it is an evident feature of genuine modal realism, via recombination (Lewis, 1986a: 87-92), that this should be so. Moreover, none of the main objections to Lewis includes, as far as I know, allegations of commitment to necessitism. So it is somewhat puzzling to suppose that the grounds for interpreting Lewis as a necessitist have been there all along, but were never noticed by his critics.

Given how surprising this interpretation is, I think it is important to clarify the reasons why Lewis is said to accept necessitism and what really follows from his acceptance of necessitism. Then, the main aim of this paper is to argue that, granted the assumptions that lead to interpret the Lewisian as a necessitist, she can still genuinely preserve the intuitions lying behind contingentism, and in doing so she can avoid the counter-intuitive consequences of standard necessitism (e.g., one defended by Williamson (2013) or Zalta and Linsky $(1994,1996))$.

The structure of this article is as follows. In Section 2, I show that the question as to whether or not Lewis accepts necessitism presupposes the controversial matter as to which the best analysis of modally modified unrestricted quantifications is for a modal realist. I will assume that the best version of modal realism endorses an analysis of unrestricted quantification in modal contexts to the effect that the modal operators are made redundant, as Williamson does. In Section 3, I explain why, granted such an analysis, the Lewisian is correctly taken to be a necessitist. In Section 4, I introduce the reasons why the Lewisian can genuinely preserve contingentist intuitions. First, as I show in Section 5, the Lewisian concurs with the folk that things could have not existed. In fact, the counter-intuitive content of necessitism is expressed, in the Lewisian perspective, by a thesis that she rejects. Second, it is in the metaphysical room that the Lewisian concurs with the folk that existence is contingent. To be sure, as I show in Section 6, saying as much means to talk in restricted terms, from a Lewisian perspective, and there is a common attitude in metaphysics, according to which theses of most interest to metaphysics are to be expressed in unrestricted terms. This attitude leads to interpret the Lewisian agreement with common sense about restricted statements as merely verbal. It is said that, if she wishes to agree with the folk, the Lewisian needs to interpret the folk discourse as restricted to some domain that is not relevant to metaphysics. It is indeed uncontroversial that the modal realist can often agree with the folk when the quantifiers are intended as restricted, while, when the quantifiers are read as unrestricted and the claims are intended as metaphysically relevant, she disagrees with them. While I take this to be true with regard to the Quinean ontological question, as I show in Section 7, the 
situation is different with modal quantified sentences, such as the necessitist thesis, as I argue in Section 8. Indeed, I claim that, sometimes, when we do modal metaphysics, we are interested in quantifiers restricted to members of metaphysical natural kinds. In Section 9, I maintain that such restricted quantifications can be useful to express theses of most interest to Lewis' metaphysics, and, finally, in Section 10, I extend the discussion to the necessitist thesis. My conclusion, in Section 11, is that it is in the metaphysical room that the Lewisian, in agreement with common sense, rejects the counter-intuitive core of necessitism. So, when the folk claim that existence is contingent, her statement does not need to be interpreted as restricted to a domain that is not relevant to metaphysics. Indeed, by saying that, the folk are stating a thesis that is metaphysically relevant for the Lewisian herself.

\section{Preliminary Clarifications}

Let us call "(N)" the thesis that "necessarily everything is necessarily something" (Williamson, 2013: 2). Two quantifiers occur in (N): "everything" and "something." Williamson (2013: 14) stipulates that, when the quantifiers in (N) are intended as absolutely unrestricted, (N) expresses the necessitist thesis. In spite of the brilliant defenses of necessitism by Williamson (2010, 2013) and Zalta and Linsky (1994, 1996), I take necessitism to be a strongly counter-intuitive thesis: it claims that it is necessary what there is, which is to say that things could not have failed to exist, while we have a pre-theoretical intuition that not everything necessarily exists, namely that it is contingent what there is. ${ }^{1}$

Now, the only reading of the quantification in $(\mathrm{N})$ for which the original version of Lewis' counterpart theory (hereafter CT), given in (1968), makes explicit provision is the restricted reading. Indeed, the original CT does not make provision for the unrestricted reading of the quantifiers when they are combined with modal operators, as it happens in $(\mathrm{N})$. According to CT, therefore, we do not have the option of reading the quantifiers in $(\mathrm{N})$ as absolutely unrestricted, as Williamson demands. Nonetheless, Lewis believes in unrestricted quantification (see, for instance, Lewis, 1991: 68; 1986a: 74). So, there is a sense in which Lewis is bound to admit that we ought to be able to make sense of $(\mathrm{N})$ when the quantifiers are absolutely unrestricted, even though CT, as we know it, was not intended to ensure that kind of quantification. Accordingly, we need to think of more than the original CT. Hence, there is the need to appeal to an extraordinary translation scheme, which offers an enriched counterpart theoretic semantics that supports both the restricted reading and the unrestricted reading of the quantifiers.

Williamson assumes a redundant approach to the matter. And the leading view is Divers' advanced modalizing (see Divers, 1999, 2002; and 2014a). Williamson

\footnotetext{
1 It might be said that there are no opinions of common sense about necessitism. In what follows, I will assume that while common sense takes necessitism to be false, it has nothing to say about the formalizations of such a thesis.
} 
does not explicitly appeal to advanced modalizing. Nonetheless, his line of reasoning largely reflects that of Divers.

The general approach at the basis of advanced modalizing consists in a redundant interpretation of the modal operators, whenever the quantifiers over individuals that occur into the scope of such modal operators are meant to be unrestricted: in other words, the modal operators are made superfluous.

However, the question as to how a modal realist should analyze modal claims involving unrestricted quantification is very controversial. ${ }^{2}$ As was hinted in Section 1, I will not explore the matter as to which is the best analysis for the modal realist of modally modified unrestricted quantifications. Williamson (2010: 665; 2013: 17) treats both occurrences of the necessity operator in (N) as redundant, and I will assume, in what follows, that Williamson is right and, hence, that Divers' approach to the matter is correct. ${ }^{3}$

Let us call "Lewis*," the Lewisian modal realist who accepts such an analysis. Once it is shown why Lewis* is correctly taken to be a necessitist, my aim in this paper is to explore the consequences of her acceptance of necessitism. This leaves open, then, the question as to whether or not the theory accepted by Lewis* is the best analysis for the modal realist of those sentences in which modal operators interact with unrestricted quantifiers. Also, this leaves open the question as to whether Lewis himself would or would not have accepted such an analysis (for arguments related to this last topic, I refer the reader to the literature about advanced modalizing).

\section{Why Lewis* Is Said to Accept Necessitism}

(N) is a thesis expressed in ordinary language. In the possible-worlds framework, the usual expression of $(\mathrm{N})$ is that, for any possible world $w$, anything that exists/is something at $w$ is such that, for any possible world $w^{\prime}$, it exists/is something at $w^{\prime}$. In other words, everything that exists at any world is something that exists in each and

\footnotetext{
${ }^{2}$ There are several alternatives in the literature to advanced modalizing. Just to name a few, see Hudson (1999); Bricker (2001); Roca-Royes (2018); and Dorr (2016). However, the aim here is to guarantee the unrestricted reading of the quantification in $(\mathrm{N})$. Hudson and Bricker's proposals, for different reasons, seem to me incapable of doing that. Roca-Royes proposes an expanded version of advanced modalizing, which, in my understanding, would not make any difference for the interpretation of $(\mathrm{N})$ unrestricted, if compared with Divers' account. Dorr, in the attempt to understand how modal realism can best be made coherent, reaches the same conclusion as Divers as to the interpretation of unrestricted quantification in modal contexts and, even though, according to Dorr, the class of sentences on which the redundant approach applies is smaller than the one supposed by Divers, it applies to $(\mathrm{N})$ unrestricted.

However, given how controversial the matter is, there are still many problems with all the accounts presented. For instance, Jago (2016) offers an analysis of some of the alternatives to the redundant approach, and he argues against all of them, including advanced modalizing; Parsons (2012) argues against Divers' account; and Marshall (2016) proposes arguments against both Divers and Dorr's proposals.

${ }^{3}$ Note, indeed, that even following Divers and Perry (2018) (who modify the redundant approach for the de re modalizing), there would be no difference in terms of the truth-value of $(\mathrm{N})$ unrestricted thus obtained, if compared with Williamson's analysis.
} 
every world, which is tantamount to the controversial thesis that everything, everywhere, necessarily exists.

We know that Lewis (1968) offers an extensionalist interpretation of modal discourse. Given his metaphysical commitments to possible worlds and counterparts (parts of worlds), Lewis reduces modal operators to quantifiers which range over such worlds and counterparts and modal operators are thus eliminated from CT. Since Lewis thinks that we ought not to extend our logic beyond first-order logic, such extensionalist interpretation of modal discourse is given in a first-order logic with identity: CT is a first-order theory.

The first important matter to deal with, then, is how the thesis $(\mathrm{N})$ can be expressed into the language of CT. Indeed, (N) must be formalized in the fundamental language of CT, so that we can wonder whether or not the formula so obtained is a theorem of CT.

According to Lewis (1968: 116-117), one can translate modal sentences of our ordinary language, such as $(\mathrm{N})$, into the language of CT either directly into CT, through what I will call the "direct strategy," or by passing through quantified modal logic (QML), by means of a "mediated strategy." The strategy Williamson employs in order to show that Lewis* is a necessitist is the mediated strategy. Hence, I will follow such a strategy and I will deal with the direct strategy only in a second moment.

Williamson first formalizes (N) in the language of QML, and then he wonders if its translation into CT turns out to be a theorem of CT. The ordinary reading of (N) in QML is given by (NNE) (Williamson, 2013: 38):

$$
(\mathrm{NNE}) \square \forall \mathrm{x} \square \exists \mathrm{y}(\mathrm{y}=\mathrm{x})
$$

(NNE) can be read either with restricted or with unrestricted quantification. ${ }^{4}$ However, as we know, only when it is read with unrestricted quantification, Williamson claims, (NNE) expresses necessitism.

According to Lewis*, who accepts the redundant interpretation, the two modal operators in (NNE) are made superfluous, and (NNE) unrestricted is translated into CT by (1) (see Williamson, 2013: 17):

$$
\forall \mathrm{x} \exists \mathrm{y}(\mathrm{y}=\mathrm{x})
$$

(1) informally says that (unrestrictedly) everything is (unrestrictedly) something. Now, (1) is a logical truth of first-order logic. ${ }^{5} \mathrm{CT}$ is a first-order theory, and all logical truths of first-order logic are theorems of such a theory.

\footnotetext{
${ }^{4}$ To be precise, a sentence of a formal language (QML), such as (NNE), cannot admit different readings, unless by "different readings" we mean that the non-logical expressions in it can be differently interpreted in different interpretations. However, in (NNE) there are no non-logical expressions. What I mean by "different readings" here is that the quantification in (NNE) can be intended as unrestricted or as implicitly restricted to a domain of things, for instance to the $P$ things, for any arbitrary predicate $P$. Formally, the restricted reading of (NNE) might thus be made explicit by a different formula such as: $\square$ $\forall \mathrm{x}(\mathrm{Px} \rightarrow \square \exists \mathrm{y}(\mathrm{Py} \wedge \mathrm{y}=\mathrm{x}))$.

${ }^{5}$ Williamson (2013: 17) claims that (1) is a trivial logical truth. Divers (2014b: 729-730) challenges Williamson to provide further explanations of the supposed triviality of the reduction of (NNE) to (1). I am not engaging with this discussion in the following.
} 
This is, therefore, the reason why Lewis* is a necessitist ${ }^{6}$ : Williamson stipulates that the debate between the contingentist and the necessitist has to be framed in unrestricted terms and, if Lewis* reads the quantification in $(\mathrm{N})$ as unrestricted, she endorses $(\mathrm{N})$.

\subsection{A Point About the Unrestricted Quantification}

Before going further, it is important to note that only Lewis* makes the thesis $(\mathrm{N})$, when read unrestrictedly, equivalent to the thesis that (unrestrictedly) everything is (unrestrictedly) something (Formula 1). The reason for this is that the domain of unrestricted quantification in CT is different from those of the other approaches. In order to see that, let us consider sentence (2): for any predicate $P$,

\section{(2) It is necessary that there is at least one $P$.}

We saw that Lewis, unlike other scholars, eliminates modal operators from his canonical language, replacing them with quantifiers over worlds (de dicto modality) and quantifiers over parts of worlds (de re modality). These quantifiers are on the same level of standard quantifiers over individuals; that is, they are all in the fundamental language of CT. Now, the quantifiers which replace modal operators should not be restricted to one world or to the parts of one world. In the canonical language of CT, we must indeed be able to quantify over all worlds and over all the entities in every world. Otherwise, for instance, we could not talk about the counterparts of an object $x$ which inhabits a world $w$ that are, at least in most cases, parts of worlds other than $w{ }^{7}$ Hence, a quantification over worlds that was restricted to the domain of just one world would make it impossible to formulate modal sentences in CT. Accordingly, removing any restriction whatsoever in the canonical language of CT means to admit in the domain of quantification any world and any part of any world. Therefore, the domain of unrestricted quantification in CT (both the standard quantifications and the quantifications which replace modal operators) is given by the totality of modal space. So, in CT's view, to speak unrestrictedly is to speak about the whole modal space.

Now, Divers claims that, as long as Lewis*'s point of view is concerned, there are two conceptions of the totality of modal space: "one as a sum of jointly exhaustive segments (worlds) and the other as the totality of modal space tout court" (Divers, 2014a: 870). According to the standard interpretation (Lewis, 1968) (which allows us only the restricted reading of the quantification in modal sentences), talking about the whole modal space means to talk about each and every world in which the whole modal space is segmented. If, instead, we think of more than the original CT and accept an enriched counterpart theoretic semantics (as we do if we want to allow also for the unrestricted reading of the quantifiers in modal contexts), then there is

\footnotetext{
${ }^{6}$ It is important to note that Lewis asserts all sorts of necessity claims about modal space as a whole. He writes: "the character of the totality of all the worlds is not a contingent matter" (Lewis 1986a: 126).

${ }^{7}$ Lewis (1983a: 43) admits that things might have counterparts in their own worlds besides themselves.
} 
another sense in which we can talk about the pluriverse: we can talk about the modal space tout court as opposed to the modal space segmented in worlds. Thus, from Lewis*'s point of view, a sentence like (2) can be true in two ways:

- The existential quantifier in (2) is read unrestrictedly: it can be true of the whole modal space that there is at least one $P$. In this case, according to advanced modalizing, as I mentioned, the modal operator becomes semantically redundant. This is because it loses its semantic function of altering the range of the quantifier over individuals that occurs within its scope (Divers, 1999: 228). Indeed, such quantifier over individuals, insofar as it is unrestricted, as I said, ranges over the whole modal space. Accordingly, (2) is true if and only if (hereafter iff) there is at least one $P$ in the pluriverse (even though it might be false that there is a $P$ in every single world).

- The existential quantifier in (2) is read restrictedly: it can be true in each world that there is at least one $P$. In this case, the modal operator is not made redundant: it retains its function of altering the range of the quantifier within its scope. Accordingly, (2) is true iff there is at least one $P$ in every world.

Therefore, on the one hand, in Lewis*'s view, as far as unrestricted quantification is concerned, its quantification is given by the whole modal space conceived tout court.

On the other hand, the domain of variation of unrestricted quantification, from the perspective of other scholars, like Williamson, is given by the entire domain of one world: removing any restriction whatsoever in the fundamental language of such theories (QML) only allows us to take into account all the entities, with no restriction, in the domain of some world at stake.

Let us go back to (2). For Williamson, as for Lewis*, talking unrestrictedly means to talk about absolutely everything. However, for Williamson, that is to say about absolutely everything, with no restriction, in the domain of some world at stake. Therefore, when he reads sentence (2) as unrestricted, he does not make the modal operator in (2) redundant, since it does alter the range of the quantifier that occurs within its scope. So, he means, as Lewis*, that necessarily there unrestrictedly is at least one $P$. However, for Williamson that is to say that there is at least one $P$ in every world, while, for Lewis*, as we saw, that is to say that there is at least one $P$ in the pluriverse (even though it is not true that there is a $P$ in every single world).

Now, recall $(\mathrm{N})$ :

(N) Necessarily everything is necessarily something.

When $(\mathrm{N})$ is read unrestrictedly, both Williamson and Lewis* mean by it that necessarily unrestrictedly everything is necessarily unrestrictedly something. However, given the disagreement between them about the domain of unrestricted quantification, in Williamson's view, that is to say that everything in any world is something in each and every world, namely that everything, everywhere, necessarily exists. By contrast, in Lewis*'s view that is to say that everything is something, which is a truth of first-order logic. 


\section{Why Lewis* Can Genuinely Preserve Contingentist Intuitions}

Once it has been explained why Lewis* is taken to be a necessitist, I now deal with the reasons why she can preserve contingentist intuitions, by genuinely agreeing with the folk that existence is contingent.

The first thing to point out is that what Lewis* endorses in the metaphysical room when she takes necessitism to be true, far from being the controversial thesis that everything, everywhere, necessarily exists, is a truth of first-order logic.

The second point to be made is that the counter-intuitive content of necessitism is expressed, in Lewis*'s view, by a thesis that she rejects. After having discussed such a thesis, I will argue that, from a metaphysical point of view, this thesis is not less relevant than necessitism. In other words, I will claim that it is in the metaphysical room that Lewis* agrees with common sense that existence is contingent; namely, it is in that room that Lewis*, in agreement with the folk, rejects the counter-intuitive core of necessitism.

\section{Lewis*'s Rejection of the Counter-intuitive Content of Necessitism}

As I mentioned, the validity of (N) unrestricted in QML implies the counter-intuitive thesis that everything in any world is something in each and every world. However, the thesis at stake does not follow from the theoremhood of $(\mathrm{N})$ unrestricted in CT; namely, it does not follow from the theoremhood in CT of the thesis that everything is something (Formula (1)). So, we should understand which thesis, if not (N) unrestricted, expresses in Lewis*'s theory the counter-intuitive content of necessitism.

The natural thought would be to consider (N) restricted. So, let us proceed, as before, through the mediated strategy, in order to translate $(\mathrm{N})$ restricted in CT. Recall that $(\mathrm{N})$ is translated into QML by $(\mathrm{NNE})$ :

$$
(\mathrm{NNE}): \square \forall \mathrm{x} \square \exists \mathrm{y}(\mathrm{y}=\mathrm{x})
$$

The important point about the translation of (NNE) into CT is that, when read with restricted quantifiers, the two modal operators in (NNE) are not made redundant. The translation into CT of QML formula (NNE) (with restricted quantification) is given by $\left(\mathrm{NNE}_{\mathrm{R}}\right)^{8}$ :

$$
\left(\mathrm{NNE}_{\mathrm{R}}\right): \forall \mathrm{x} \forall \mathrm{y}\left(\mathrm{Wy} \wedge \mathrm{Ixy} \rightarrow \forall \mathrm{z}\left(\mathrm{Wz} \rightarrow \forall \mathrm{x}_{1}\left(\mathrm{Ix}_{1} \mathrm{z} \wedge \mathrm{Cx}_{1} \mathrm{x} \rightarrow \exists \mathrm{x}_{2}\left(\mathrm{Ix}_{2} \mathrm{z} \wedge \mathrm{x}_{2}=\mathrm{x}_{1}\right)\right)\right)\right)
$$

(where " $W$ " stands for "world", " $P$ " for "to be in a possible world", and " $C$ " for "to be a counterpart of"). ( $\left.\mathrm{NNE}_{\mathrm{R}}\right)$ is a theorem of CT. ${ }^{9}$ And it is pretty obvious that is so. In order to illustrate this point, let us say that $\left(\mathrm{NNE}_{\mathrm{R}}\right)$ is a theorem of CT iff it

\footnotetext{
8 The rules of original CT (Lewis 1968: 118) of translation of a formula of QML into a formula of CT relevant to this paper are the following (where " $\phi \mathrm{x}$ " is an open sentence and $(\phi \mathrm{x})^{\mathrm{w}}$ means " $\phi x$ is true in the world $w$ ):

$(\forall \mathrm{x} \phi)^{\mathrm{w}}$ is $\forall \mathrm{x}\left(\mathrm{Ixw} \rightarrow \phi^{\mathrm{w}}\right)$.

$(\exists \mathrm{x} \phi)^{\mathrm{w}}$ is $\exists \mathrm{x}\left(\mathrm{Ixw} \wedge \phi^{\mathrm{w}}\right)$.

$(\square \phi x)^{\mathrm{w}}$ is $\forall \mathrm{y} \forall \mathrm{z}\left(\mathrm{Wy} \wedge \mathrm{Izy} \wedge \mathrm{Czx} \rightarrow \phi^{\mathrm{y}} \mathrm{z}\right)$.

${ }^{9}$ Lewis (1968: 119) discusses another formula that is weaker than (NNE), that is, (NE): $\forall x \square \exists y(y=x)$.
} 
comes out true in every description of the pluriverse that is consistent with the axioms of CT. $\left(\mathrm{NNE}_{\mathrm{R}}\right)$ is true iff all the counterparts of every $x$ in every world are such that, in their worlds, they are something. But of course, if there is a counterpart $x_{1}$ of $x$ in some world $z$, then $x_{1}$ is something in $z$. Therefore, there is no description of the pluriverse in which $\left(\mathrm{NNE}_{\mathrm{R}}\right)$ could fail, and $\left(\mathrm{NNE}_{\mathrm{R}}\right)$ is a theorem of $\mathrm{CT}$. ${ }^{10}$

However, $\left(\mathrm{NNE}_{\mathrm{R}}\right)$ does not express the counter-intuitive content of necessitism. $\left(\mathrm{NNE}_{\mathrm{R}}\right)$ says that all the counterparts of every $x$ in every world are such that, in their worlds, they are something. As a matter of fact, $\left(\mathrm{NNE}_{\mathrm{R}}\right)$ seems to lack any relevance at all in the debate about necessitism.

The thesis that intuitively expresses the counter-intuitive core of necessitism in counterpart theoretic terms, instead, is (3):

(3) Everything, in every world, has at least one counterpart in every world. ${ }^{11}$

And (3) is nothing but $(\mathrm{N})$, read by Lewis* with restricted quantification. Indeed, recall that $(\mathrm{N})$ says that, for any possible world $w$, everything that exists/ is something at $w$ is such that, for any possible world $w^{\prime}$, it is identical to something that exists/is something at $w^{\prime}$. Let us assume that anything that exists/is something at a world is in the domain of quantification of that world. Restrictedly speaking, in Lewis' words, being in the domain of the quantification of a world means to belong "to the least restricted domain that is normally-modal metaphysics being deemed abnormal - appropriate in evaluating the truth at that world of quantifications" (Lewis, 1983a: 40). This domain includes every part of the world of quantification and nothing else. When Lewis* interprets the existence in the domain of restricted quantification of a world as existence according to that world (that is, as existence through a counterpart that is part of that world, and not only as being part of that world), (N) comes to mean (N'):

(N') For any possible world $w$, anything that is part of $w$ is such that, for any possible world $w^{\prime}$, it exists according to $w^{\prime}$ (through at least one counterpart).

And (N') is nothing but (3). Therefore, (3) is equivalent to $(\mathrm{N})$ read by Lewis* with restricted quantifiers, namely to ( $\left.\mathrm{N}^{\prime}\right)$, and it is (3) that expresses the counterintuitive content of necessitism, from Lewis*'s perspective.

Now, (3) is not a theorem of CT. Indeed, the regimentation of (3) into CT is given by the Formula (3'):

$$
\left(3^{\prime}\right) \forall \mathrm{x} \forall \mathrm{y}\left(\mathrm{Wy} \wedge \mathrm{Ixy} \rightarrow \forall \mathrm{z}\left(\mathrm{Wz} \rightarrow \exists \mathrm{x}_{1}\left(\operatorname{Ix}_{1} \mathrm{z} \wedge \mathrm{Cx}_{1} \mathrm{x}\right)\right)\right)
$$

\footnotetext{
${ }^{10}$ Note that $\left(\mathrm{NNE}_{\mathrm{R}}\right)$ is a logical truth of first-order logic. Indeed, if a formula has a valid consequent, then that formula is valid. And the consequent of the second conditional of $\left(\mathrm{NNE}_{\mathrm{R}}\right)\left[\forall \mathrm{x}_{1}\left(\mathrm{Ix}_{1} \mathrm{z}^{\wedge}\right.\right.$ $\left.\left.C \mathrm{x}_{1} \mathrm{x} \rightarrow \exists \mathrm{x}_{2}\left(\mathrm{Ix}_{2} \mathrm{z}^{\wedge} \mathrm{x}_{2}=\mathrm{x}_{1}\right)\right)\right]$ is valid: it only says that, for everything that is in some relation $I$ with $z$ and in some relation $C$ with $x$, there is something that is identical to it and which is in relation $I$ with $z$. Since CT is a first-order theory, all logical truths of first-order logic are theorems of such a theory.

11 It is well-known that, for Lewis (1986a: 198-210), while individuals are world-bound (that is, each individual is only part of one world), they can exist according to more than one world through their counterparts.
} 
And (3') does not follow from the axioms of CT. Certainly, there are semantically admissible descriptions of the pluriverse in which (3') comes out true. However, in order to show that ( $\left.3^{\prime}\right)$ is not a theorem of CT, we only need a counterexample: a description of the pluriverse that is consistent with the axioms of CT and in which (3') fails. And it is easy to find such a counterexample. As hinted in Section 1, let us take a description of the pluriverse in which the Lewisian principle of recombination, which is not a theorem of CT, holds. According to such a principle, roughly speaking, anything can coexist with anything, and anything can fail to coexist with anything (Lewis, 1986a: 90). So, combinations of fewer things than there are in some world are possible. Since Lewis formulates the principle of recombination in terms of duplicates of individuals, rather than counterparts (Lewis, 1986a: 88, 89), let us suppose that the description we are considering is one in which the counterpart relation coincides with the duplicate relation. In such a description of the pluriverse, the thesis that everything everywhere has a counterpart in every world is false. And that is a counterexample to the theoremhood of (3'). Lewis writes, indeed, that "it would not have been plausible to postulate that, for any two worlds, anything in one had some counterpart in the other" (1968: 116).

Therefore, (3') expresses, in Lewis*'s view, the thesis that would contradict common sense, namely the thesis that things could not have failed to exist. And Lewis* rejects (3'). In other words, she rejects what is counter-intuitive about necessitism.

Note that, in order to get to (3'), we had to use the direct strategy: we started with $(\mathrm{N})$ restricted, a sentence of our ordinary language, and we directly translated it into CT as (3'). If we follow, instead, the mediated strategy, as we saw, then the only translation into $\mathrm{CT}$ of $(\mathrm{N})$ restricted to take into account would be $\left(\mathrm{NNE}_{\mathrm{R}}\right)$. However, $\left(\mathrm{NNE}_{\mathrm{R}}\right)$ does not express the counter-intuitive content of necessitism and it seems to lack any relevance in the debate about necessitism. In addition, what is counter-intuitive about necessitism - which is given by (3') — would not be expressible at all in CT, since (3') is not translatable into QML. Hence, there would be no way to express in CT the counter-intuitive core of necessitism, and no chance of showing that Lewis* rejects $(\mathrm{N})$ restricted (which expresses what is counter-intuitive about necessitism). In what follows, then, I will take for granted that we should adopt the direct strategy: it gives us (3'), which is a plausible translation of $(\mathrm{N})$ restricted into $\mathrm{CT}$, and it is the only relevant restricted reading of $(\mathrm{N})$ from Lewis*'s perspective in such a debate. $^{12}$

\footnotetext{
12 It might be interesting to note that Williamson, in the context of saying that modal realists endorse necessitism, claims that "[a]lthough modal realists deny that everything in one world has a counterpart in every other world [...], the generalization [...] thereby denied ha[s] world-restricted quantifiers and do[es] not express necessitism" (2013: 17). In this quote, Williamson seems to talk about the restricted reading of the necessitist thesis $(\mathrm{N})$. About that, Williamson claims that it does not express necessitism and that modal realists deny it. Now, we know that the translation into CT of (NNE) restricted, $\left(\mathrm{NNE}_{\mathrm{R}}\right)$, is a theorem of CT. Hence, the thesis he is talking about and that the modal realists reject cannot be (NNE) restricted. In this quote, indeed, he is clearly talking about (3'), which, as we know, is rejected by modal realists. This means that Williamson seems to take (3') as the restricted reading of (N) as well, and hence seems to accept the direct strategy: it is only through the direct strategy that we can get (3') as the restricted reading of $(\mathrm{N})$; according to the mediated strategy, instead, the restricted reading of $(\mathrm{N})$ is only given by $\left(\mathrm{NNE}_{\mathrm{R}}\right)$.
} 


\section{6 (N) Restricted Is a Thesis Relevant to Lewis*'s Metaphysics}

As for the reasons why Lewis*'s theory, in agreement with common sense, can deny what is counter-intuitive about necessitism, I said so far that:

- What Lewis* endorses in the metaphysical room when she takes necessitism to be true is a truth of first-order logic.

- Only for Lewis*, necessitism can be true even though it is false that everything at any world is something in each and every world, namely, even though (3'), which expresses the counter-intuitive content of necessitism in counterpart theoretic terms, is false. That is to say that, only for Lewis*, necessitism is true even though things could have failed to exist.

Now, we know that (3') is the translation into CT of $(\mathrm{N})$ restricted. Therefore, from Lewis*'s perspective, denying ( ${ }^{\prime}$ ') and saying that things could have failed to exist means to talk in restricted terms.

I said that it is by virtue of a stipulation that $(\mathrm{N})$ expresses necessitism only when it is read as unrestricted. However, Williamson claims that the stipulation is not arbitrary, because " $[\mathrm{t}]$ he generalizations of most interest to metaphysics are unrestricted" (Williamson, 2014: 759). Williamson's claim mirrors a common attitude in metaphysics: unrestricted generalizations appears mandatory to metaphysical discourse. For instance, for a claim like, say, "everything is located in space-time" to have the force the metaphysicians want it to have, "everything", it is said, needs to refer to absolutely everything; otherwise, it would not be a claim relevant to metaphysics.

Now, it is highly contentious if a quantification over absolutely everything is even possible (see Rayo \& Uzquiano, 2006, for a summary of the problems related to this matter). I remain neutral on this point. However, my arguments in the following are intended mainly for the reader who accepts unrestricted quantification and, like Williamson, believes that it is mandatory to metaphysical talk. I aim to convince her that Lewis* can make interesting metaphysical claims while talking restrictedly. I expect, indeed, that for the reader who does not accept unrestricted quantification, many of my arguments in the following should be less controversial.

\section{The Quinean Ontological Question}

I assume that Lewis*, as well as Lewis, would agree with Williamson that unrestricted quantification is needed, insofar as the Quinean ontological question "what is there?" is concerned. Williamson says:

At the core of metaphysics is ontology. Quine poses the ontological problem by asking "What is there?", and answers, correctly but uninformatively. "Everything" [...]. To interpret his question and answer as restricted to a domain that excludes some contextually irrelevant things would be to misunderstand Quine by losing the total generality of the problem that he means to raise (2003: 415). 
Lewis* would concur with Williamson that, in order to be relevant to metaphysics, the Quinean ontological question should be read with unrestricted quantification. The Quinean ontological question is, in fact, about what there unrestrictedly is. So, whenever Lewis* wants to make an ontological claim about what there is or what there is not, she should talk unrestrictedly. Indeed, she might want to respond to such a question by saying, for instance, that there are talking donkeys. And for that to be true, Lewis* must read the quantification as unrestricted, so that she is allowed to also take into account other worldly-things and not only the actual things. Read restrictedly, indeed, from a Lewisian point of view, such a sentence would come to say that there actually are talking donkeys. And that is false. Lewis*, thus, agrees with Williamson that the primary ontological question must be discussed in unrestricted terms.

Certainly, the question "what is there actually?" is a respectable one, so that, in some contexts, for instance when Lewis* wants to talk with the folk (who are supposedly actualist), the restricted reading of the quantification might be the privileged reading. In such a context, Lewis* can agree with the folk that there are no talking donkeys, by restricting her quantifiers and, thus, she might sound as an actualist. However, we know that she is not an actualist. Therefore, such an agreement is not intended to be genuine: in the metaphysical room, Lewis* believes that there are talking donkeys and, thus, she intends to disagree with the folk. Indeed, in order to agree with the folk, the Lewisian needs to interpret the folk discourse as restricted to some domain that is not relevant to metaphysics. And we will see in the following that the restriction to the actual world is a restriction to a domain that is not relevant to Lewis*'s metaphysics. Moreover, from Lewis*'s perspective, "what is there actually?" is also a semantically infected question, turning largely on the matter of which part of modal space it is that we want to delimit by the use of the indexical term "actually" (see, for instance, Lewis, 1986a: 92-96).

So, as far as the Quinean ontological question is concerned, the only reading of the quantification that serves theses that are of interest to metaphysics is the unrestricted one. And Lewis* would agree with Williamson on this point.

However, the situation is different with modal quantified sentences, such as $(\mathrm{N})$.

\section{About the Methodology of Modal Metaphysics}

When it comes to the methodology of modal metaphysics, I claim that there are two significant points of agreement between Lewis* and who believes, like Williamson, that theses of most interest to metaphysics are to be expressed in unrestricted terms. ${ }^{13}$

First of all, they agree that the right way to do modal metaphysics is to combine modal operators with unrestricted quantifiers, because modal metaphysics would naturally be taken to be about modal modifications of unrestricted quantifiers. There are, indeed, tokens of sentence type that Lewis* endorses and that require unrestricted quantification in order to be true. For instance, Lewis* wants to state things

\footnotetext{
${ }^{13}$ Of course, there are important limits on the agreement. For instance, Lewis* thinks that modal language must be reduced to a non-modal language, while other authors, like Williamson, think that it is metaphysically fundamental.
} 
like "it is possible for there to be many possible worlds", and the unrestricted reading of the quantification in a sentence like that is needed for making it true. ${ }^{14}$

Second, I argue that they should also agree that, sometimes, when we do modal metaphysics, we are interested in unrestricted quantifiers sorted by predicates that pick out members of metaphysical natural kinds. For instance, granted that we need the unrestricted quantifiers in order to talk about absolutely everything, when we do biology we also need to restrict the quantifiers to entities which belong to biological natural kinds. When we do physics, instead, we need to restrict the quantifiers by means of predicates that pick out members of physical natural kinds. Therefore, when we do metaphysics, sometimes, we use predicates that restrict our quantification to members of metaphysical natural kinds. ${ }^{15}$ Thus, I claim that it is a relevant thesis for metaphysics if one says that, among all the things that there unrestrictedly are, the $F$ things are so and so, if $F$ picks out members of a metaphysical natural kind according to one's metaphysical theory. ${ }^{16}$

\subsection{Metaphysical Natural Kinds}

Of course, the agreement about the methodology of modal metaphysics can leave room for some disagreement over what the metaphysical natural kinds are for one's theory.

Lewis distinguishes between "ordinary" and "extraordinary" individuals. Ordinary individuals are those individuals whose parts are spatiotemporally connected to each other. Since possible worlds are unified by the spatiotemporal interrelations of their parts, ordinary individuals are world-bound individuals. ${ }^{17}$ By contrast, extraordinary individuals are individuals composed of parts from different worlds: they are trans-world individuals composed of parts that are not spatiotemporally connected to each other. Then, Lewis claims (1986a: 210-211) that ordinary things are the things we are mostly interested in when we do metaphysics. ${ }^{18}$

Therefore, I take it that, for Lewis*, the ordinary individuals constitute a metaphysical natural kind. If I am right in saying that we are allowed to restrict the quantification by means of predicates that pick out metaphysical natural kinds when we do modal metaphysics, this means that Lewis* is allowed to cut down unrestricted

\footnotetext{
14 We know, indeed, that according to the restricted reading, the sentence at stake would come out false, since there is no world in which there are many possible worlds.

15 The idea is to take into account non-arbitrary classes of things that are of special interest to a science (be it biology, physics, or metaphysics). I am going to use the term "natural kind" for that, but I do not mean to imply all that people usually mean to imply by using the term "natural kind." So, for instance, I do not need to take it to be the nature discovered by science (as naturalness is understood in the Lewisian framework), nor do I need to assume that to be a member of the kind is an essential feature, and so forth.

16 This should be similar, in some respects, to what Williamson (2003: 436-443) calls "kind-generalizations." At any rate, in the next section, I will present examples of what we might take to be metaphysical natural kinds for both Lewis* and Williamson.

17 Note that, among the ordinary individuals there are individuals that we would not usually call "ordinary": there are all the sums of spatiotemporally connected parts. According to Lewis (1986a: 211-213), indeed, composition is deemed to be unrestricted.

18 He even calls the extraordinary individuals, with a problematic terminology, "impossible individuals" (see, for instance, Lewis 1986a: 211).
} 
quantification over the whole modal space tout court to the metaphysical natural kind constituted by ordinary individuals. In order to operate such a restriction, Lewis* has to restrict the quantifiers over individuals by means of the predicate of CT " $I$ " (which stands for "is part of"). Let us consider again our sentence (2):

(2) It is necessary that there is at least one $P$.

Reading the quantification in (2) as unrestricted, from Lewis*'s perspective, as we know, is to say that there is at least one $P$ in the pluriverse, that is, " $\exists \mathrm{x}$ Px". By restricting the quantification over individuals in (2) by means of the predicate " $P$ ", we have that there is at least one $P$ in $w$, for every world w. Note that, in so doing, we also make use of the quantifier over worlds, which retains, in this context, its semantic function: $\forall \mathrm{x}(\mathrm{Wx} \rightarrow \exists \mathrm{y}(\mathrm{Iyx} \wedge \mathrm{Py}))$. Therefore, by restricting the quantifiers to ordinary individuals, Lewis* no longer talks about what is true of the pluriverse tout court, but about what is true in every (some) one of the possible worlds into which the pluriverse is segmented.

Another way to put it is that, when Lewis* unrestrictedly quantifies over the pluriverse tout court, she quantifies over absolutely everything: ordinary and extraordinary things. When, instead, she restricts her quantifiers by means of the predicate " $P$ " and, so, she takes into account only the ordinary things, she approaches the pluriverse as the sum of jointly exhaustive worlds. ${ }^{19}$ Therefore, I claim that Lewis* can express metaphysically relevant claims while talking restrictedly, as long as the restrictions are to ordinary things and, so, to possible worlds.

If, instead, we take into account what, say, Williamson presumably would take to be a metaphysical natural kind, we would have a different choice since, of course, he has a different metaphysical theory. Indeed, Williamson would take, I believe, the distinction between abstract and non-abstract things to have a metaphysical value. Thus, we can say that, for him, among other things, abstract things and non-abstract things constitute metaphysical natural kinds (see, for instance, Williamson, 2013). By contrast, for Lewis* (Lewis, 1986a: 81-86), such a distinction is of no interest to metaphysics, in the sense that it is a distinction that is more in need of explanation than it has capacity to be an explainer.

Therefore, I claim that, while theses relevant to metaphysics are expressed in unrestricted terms, quantifications restricted by means of predicates which pick out metaphysically natural kinds are also relevant in metaphysics, no matter what the metaphysical natural kinds are for one's theory.

Note that Lewis* would agree with Williamson that not all the restrictions can serve theses of relevance to metaphysics: there are restrictions of the quantification that are arbitrary, by being metaphysically uninteresting. For instance, let us suppose that Williamson and Lewis* decide to cut down unrestricted quantification to, say, tables. Well, whatever they might say about tables, that restriction would not serve theses of interest to metaphysics. In fact, even though tables are both non-abstract

\footnotetext{
19 Indeed, I could have started by taking the possible worlds as constituting a metaphysical natural kind for Lewis*. Since the reader must be comfortable in accepting at least one, between the possible worlds and the ordinary individuals, as forming a metaphysical natural kind for Lewis*, and since the restriction would work in the same way in both cases, then in what follows I will take it that both possible worlds and ordinary individuals constitute metaphysical natural kinds for Lewis*.
} 
and ordinary objects, tables do not constitute a metaphysical natural kind for either of them: tables constitute only an arbitrary subset of a metaphysical natural kind.

Now, from Lewis*'s perspective, restricting the quantification to what there is in the actual world, that is to the actual ordinary things, is not of much interest to metaphysics, since the actual does not constitute a metaphysical natural kind for Lewis. However, it still has some interest to metaphysics: unlike the restriction to tables, this is a metaphysically interesting way, from her perspective, to individuate subsets of ordinary things.

Indeed, it is true, on the one hand, that for Lewis there is no metaphysical distinction between the actual ordinary individuals and the possible ones, so that the actual does not represent a metaphysical natural kind for him. On the other hand, however, Lewis' claim that there is no metaphysical distinction between the actual and the possible should be read in the context of his replies to the ersatzists (Lewis, 1986a). In that context, Lewis wants to deny those differences between the actual and the possible that the ersatzists insist on (such as, for instance, that unlike other worlds, the actual world is concrete; that unlike actual worldly-things, other worldly-things would only have existed but they do not, and so on). So, when the metaphysical differences between the actual and the possible are those that the ersatzists have in mind, then Lewis denies that there are such differences. However, Lewis does not need to say that there is no metaphysical difference at all between the actual and the non-actual. Indeed, sometimes we have theses of some interest to metaphysics when we restrict our quantification to the actual ordinary things, since they constitute an interesting subset of a metaphysical natural kind, for Lewis*.

We saw that, when Lewis* wants to answer the Quinean ontological question, she must talk unrestrictedly. Indeed, in this case, only unrestricted quantification can serve theses that are relevant to metaphysics: the restriction to actuality does not matter in this case. However, once you have drawn the boundary of the actual, there are different kinds of facts that are true in that domain and that are of some interest to metaphysics. Indeed, the actual world, from Lewis' perspective, seems to behave well in some metaphysically important respects. So, the actual world differs metaphysically from (some) other worlds in being, say, such that physicalism holds in it, in being law-governed (see, for instance, Lewis, 1986a), and so on. For instance, let us consider sentence (4) below. Lewis is a materialist, so he believes (4) to be true (see, for example, Lewis, 1983b: 361-362):

(4) Everything is material.

(4) is supposed to be a metaphysical commitment. However, Lewis does not believe that unrestrictedly everything is material; rather he believes that materialism is "[...] a merit of our world that not all other worlds share" (Lewis, 1983b: 362). Therefore, for sentence (4) to be true, the restricted reading of the quantification is required: (4) must be read as saying that everything in the actual world is material, or that every actual ordinary thing is material. Such a thesis is of some interest to metaphysics. Nonetheless, the fact remains that it is not a fundamental issue of metaphysics, since the actual does not constitute a metaphysical natural kind. Moreover, we should bear in mind that, no matter 
how interesting it may appear to Lewis*'s metaphysics, from her own point of view, it is a semantically infected thesis. ${ }^{20,21}$

Hence, when one does metaphysics, one is not allowed to arbitrarily cut down the quantification to things like tables, unless tables are taken to constitute a metaphysical natural kind for one's theory. And, in this sense, it is true what Williamson claims: theses relevant to metaphysics are not served by the restricted reading of the quantification. However, my crucial point is that when one restricts the quantification with predicates that pick out what she takes to be metaphysical natural kinds, she is allowed to do metaphysics: metaphysically relevant claims can be expressed in restricted terms, as long as the restrictions are not arbitrary.

\section{Examples About Lewis*'s Restricted Reading of the Quantification}

In this section, I will analyze some metaphysical claims, hoping to convince the reader that the quantifications restricted to members of metaphysical natural kinds can be useful to express theses of most interest to Lewis*'s metaphysics.

Let us consider the following sentence ${ }^{22}$ :

(5) It is contingent that everything is material.

We know that Lewis* is a materialist. However, she believes that materialism is a contingent thesis (see Lewis, 1983b: 362). So, (5) is something that Lewis* wants to be true. And it seems to me evident that (5) says something relevant about Lewis*'s metaphysics.

The unrestricted reading of the quantification in (5), however, would make it false. First of all, speaking unrestrictedly, it is not true that everything is material. Secondly, facts about the pluriverse are not a contingent matter (see Lewis, 1986a: 126). Therefore, since it is false of the pluriverse that everything is material, then it is necessarily false that unrestrictedly everything is material. That is to say, far from being true that it is contingent that everything is material, speaking unrestrictedly, from Lewis*'s perspective, it is necessarily false that everything is material.

Therefore, in order to make (5) true, which is a fundamental issue of metaphysics, Lewis* must read (5) restrictedly. This means that, even within the expanded counterpart theoretic semantics, the metaphysically relevant reading of (5) is the restricted one. According to such a reading, (5) claims that there are worlds in which everything is material and worlds in which materialism is false.

\footnotetext{
${ }^{20}$ Recall, indeed, that by virtue of the Lewisian indexical theory, matters about the actual turn largely on the question of which part of modal space it is that we want to delimit by the use of the indexical term "actually.".

21 A parallel might be built with Williamson. From his perspective, a metaphysically interesting way to individuate subsets of non-abstract things is to distinguish between concrete and non-concrete things (see, for instance, Williamson 2013: 7).

22 See Dorr (2016) for a discussion about the contingency in Lewis's view. At any rate, here the point is not just that Lewis cannot make contingent claims true, when read unrestrictedly, while he can make them true, when read restrictedly, as Dorr already points out. Rather, that some of these claims are metaphysically relevant, when read restrictedly.
} 
Sentence (5) restricted sees the pluriverse as the sum of the worlds in which the pluriverse is segmented, rather than as the totality of modal space tout court. Nonetheless, (5) is a relevant thesis to metaphysics.

The same holds, of course, for other sentences that Lewis* wants to assert related to materialism (see Lewis, 1966), such as "it is contingent that there are no immaterial things"; "it is possible for there to be no material things"; "it is contingent that every mental state is a physical state"; and so on. Also, the thesis of Humean supervenience is believed by Lewis (1986b: Introduction ix) to be contingent. So, Lewis* believes that:

(6) It is contingent that everything supervenes on the arrangement of qualities of points or point-sized entities and on their mutual spatiotemporal relations.

And what she means by (6) is that there are worlds (worlds like ours) in which this is true, and worlds in which this is false (see Lewis, 1986b: x-xi; 1994: 474-475).

Let us now consider sentence (7):

(7) It is necessary that there is something.

According to the unrestricted reading of the quantification in (7), (7) claims that there unrestrictedly is something, and it is true, for Lewis*, that there unrestrictedly is something rather than nothing: "there is logical space, the totality of the worlds in all their glory" (Lewis, 1986a: 74). Read restrictedly, (7) claims that in every possible world there is something. And also this is true for Lewis*: in each world in which the pluriverse is segmented there is something (see Lewis, 1991: 10-14). ${ }^{23}$

Therefore, (7) is true in Lewis*'s view, both on the restricted and the unrestricted interpretation of the quantifier (see Lewis, 1986a: 74). What matters here, however, is that both readings seem to serve theses that are of most interest to metaphysics. Saying that in every world there is something seems, indeed, to be at least equally interesting to metaphysics as saying that there is something in the pluriverse. ${ }^{24}$

For sure, the thesis that in every world there is something might also be expressed in unrestricted terms by sentence (8):

(8) There are no empty worlds.

Indeed, it might be the case that everything that is relevant for the metaphysics can be expressed in unrestricted terms. However, I do not need to rule out that it might be the case that, for every metaphysical thesis discussed in restricted terms, there might be, in principle, a reformulation in unrestricted terms. I only want to show that the restricted reading of the quantification can convey theses that are as metaphysically relevant as the theses expressed in unrestricted terms. Then, my point is that, once we have expanded the counterpart theoretic semantics in order to admit also the unrestricted reading of the quantifiers that we need for doing modal metaphysics, we still have the restricted reading, and the restricted reading might turn out to express metaphysically relevant claims. In other words, while we need reasons for extending the semantics of original $\mathrm{CT}$, the restricted reading is already there: we already have the restricted reading.

\footnotetext{
23 Very roughly, Lewis (1991: 10-15) rejects the possibility of empty worlds because he rejects the null individual in mereology.

24 One can think of the literature related to the first topic, also stimulated by the Lewisian rejection of empty worlds (just to name a few works, see Baldwin 1996; Coggins 2010).
} 
The above should confirm that theses served by the restricted reading can belong to metaphysics just as well as theses served by the unrestricted reading. And what makes the sentences discussed in this section express theses of most interest to metaphysics is the fact that the quantification in them is not arbitrarily restricted: the quantification is restricted to the worlds and, thus, to the ordinary things, and we saw that, for Lewis*, they constitute metaphysical natural kinds.

\section{Back to (N)}

Let us go now back to the necessitist thesis (N), and let us see what conclusions can be drawn:

(N) Necessarily everything is necessarily something.

Williamson writes: "Nobody accepts the corresponding arbitrarily restricted schema 'Necessarily every $\mathrm{F}$ is necessarily some F' as valid for all substitutions for ' $F$ ', since it excludes the possibility of being contingently $F$. A baker is contingently a baker" (2013: 14).

(N) is a thesis of most interest to metaphysics. I argued that, when one wants to state a relevant metaphysical thesis, one can use either unrestricted quantification or restricted quantification over metaphysical natural kinds. That is, as Williamson claims, one cannot arbitrarily restrict the quantification in $(\mathrm{N})$ : arbitrary restrictions would not be of interest to metaphysics. Accordingly, it would be of no interest to metaphysics restricting the quantification in $(\mathrm{N})$ in the following way (unless one takes table to constitute a metaphysical natural kind):

(9) Necessarily every table is necessarily some table.

However, one might restrict the quantifiers in $(\mathrm{N})$ to what Lewis* takes to constitute a metaphysical natural kind. Lewis* can say that $(\mathrm{N})$, as most of the theses of interest to metaphysics, is about ordinary things:

(10) Necessarily every ordinary thing is necessarily some ordinary thing.

Now, according to CT, for an ordinary thing to be necessarily some ordinary thing, it must have an ordinary thing as a counterpart in every world. (10) claims, then, that everything in every world has a counterpart in every world. Clearly, (10) corresponds to Formula (3’). And, as we saw, Lewis* rejects $\left(3^{\prime}\right) .^{25}$

\footnotetext{
${ }^{25}$ Interestingly, if we restrict the quantifiers in $(\mathrm{N})$ to what Williamson takes to be a metaphysical natural kind, we get:

(11) Necessarily every non-abstract thing is necessarily some non-abstract thing.

He claims (2013: 15) that, if the paradoxes of set theory were only generated by unrestricted quantifiers, then the necessitism/contingentism debate would survive with a restricted version of $(\mathrm{N})$, that is, with (11). He rejects the assumption about the paradoxes. Nonetheless, if it were the case, he claims, it would still make sense to talk about necessitism in a restricted version, because (N), Williamson says, is about non-abstract objects. I claim that what would make (11) a plausible restricted version of $(\mathrm{N})$ is that $(\mathrm{N})$ is about a fundamental metaphysical issue and, as such, it concerns a metaphysical natural kind, namely, the one constituted by non-abstract objects. Therefore, since (11) restricts the quantifiers to non-abstract things, then (11) might be a metaphysically relevant restriction of $(\mathrm{N})$. And the same applies to Lewis*, who can say that $(\mathrm{N})$ is about ordinary things.
} 
Therefore, I claim that Lewis* is entitled to talk, in the metaphysical room, about $(\mathrm{N})$ in a restricted way, through sentence (10). From a methodological point of view, (10) is the result of combining unrestricted quantification with Lewis*'s own choice of natural predicates. When Lewis* rejects $(\mathrm{N})$ (that is, when she reads $(\mathrm{N})$ restrictedly), she is not denying necessitism. Recall indeed that it is stipulated that necessitism is expressed by $(\mathrm{N})$ unrestricted. However, she is denying a thesis that is of most importance to metaphysics. And it is this thesis, I claim, that the folk reject. So, it is in the metaphysical room that Lewis* agrees with the folk that existence is contingent: it is in that room that Lewis*, in agreement with common sense, rejects the counter-intuitive core of necessitism. In other words, when Lewis* agrees with the folk that things could have failed to exist, she does not need to interpret the folk belief as restricted to a domain that is irrelevant to metaphysics.

\section{Conclusion}

In this paper, I explained why Lewis* is taken to be a necessitist. I showed that what Lewis* endorses, when she takes necessitism to be true, is a truth of first-order logic, and that she rejects the thesis that everything at any world is something in each and every world. I argued that the latter thesis, which expresses the counter-intuitive content of necessitism, despite being restricted on Lewis*'s interpretation, is as relevant as the necessitist thesis is, from a metaphysical point of view. In other words, I claimed that it is in the metaphysical room that Lewis* can deny what is counter-intuitive about necessitism. This means that, despite being a necessitist, Lewis* can genuinely preserve contingentist intuitions: her theory genuinely agrees with the reasons why the folk reject the counter-intuitive core of necessitism. Put differently, it is in the metaphysical room that Lewis* agrees with the folk that things could have failed to exist, even though in the very same metaphysical room she agrees with Williamson that necessitism is true.

To conclude, while nothing interesting would follow from saying that Lewis* is a necessitist (namely, from the fact that she accepts a truth of first-order logic), something interesting, also from a metaphysical point of view, follows from her rejection of the counter-intuitive core of necessitism.

Acknowledgements I am very grateful to Giorgio Lando, John Divers, Pasquale Frascolla, Andrea Iacona and Daniele Sgaravatti who gave their time to help me improve this work.

Funding Open access funding provided by Università degli Studi di Napoli Federico II within the CRUICARE Agreement. Università degli Studi di Napoli Federico II, Dipartimento di Studi Umanistici.

\section{Declarations}

Conflict of Interest The author declares no competing interests. 
Open Access This article is licensed under a Creative Commons Attribution 4.0 International License, which permits use, sharing, adaptation, distribution and reproduction in any medium or format, as long as you give appropriate credit to the original author(s) and the source, provide a link to the Creative Commons licence, and indicate if changes were made. The images or other third party material in this article are included in the article's Creative Commons licence, unless indicated otherwise in a credit line to the material. If material is not included in the article's Creative Commons licence and your intended use is not permitted by statutory regulation or exceeds the permitted use, you will need to obtain permission directly from the copyright holder. To view a copy of this licence, visit http://creativecommons.org/licen ses/by/4.0/.

\section{References}

Baldwin, T. (1996). There might be nothing. Analysis, 56(4), 231-238.

Bricker, P. (2001). Island Universes and the Analysis of Modality. In G. Preyer \& F. Siebelt (Eds.), Reality and Humean Supervenience: Essays on the philosophy of David Lewis (pp. 27-55). Rowman \& Littlefield.

Bricker, P. (2014). The methodology of modal logic as metaphysics. Philosophy and Phenomenological Research, 88(3), 717-725.

Coggins, G. (2010). Could there have been nothing? Against Metaphysical Nihilism. Palgrave-Macmillan.

Divers, J. (1999). A genuine realist theory of advanced modalizing. Mind, 108(430), 217-240.

Divers, J. (2002). Possible worlds. Routledge.

Divers, J. (2014a). The modal status of the Lewisian analysis of modality. Mind, 123(491), 861-872.

Divers, J. (2014b). Modal reality and (Modal) logical space. Philosophy and Phenomenological Research, $88(3), 726-733$.

Divers, J., \& Perry, J. J. (2018). Advanced modalizing de dicto and de re. Analysis, 78(3), 415-425.

Dorr, C. (2016). How to be a modal realist. https://philarchive.org/archive/DORHTBv1. Accessed 14 May 2020.

Hudson, H. (1999). A true necessary falsehood. Australasian Journal of Philosophy, 77(1), 89-91.

Jago, M. (2016). Advanced modalizing problems. Mind, 124(499), 627-642.

Lewis, D. (1966). An argument for the identity theory. The Journal of Philosophy, 63(1), 17-25.

Lewis, D. (1968). Counterpart theory and quantified modal logic. The Journal of Philosophy, 65(5), $113-126$.

Lewis, D. (1983a). Postscripts to "Counterpart theory and quantified modal logic." In D. Lewis (Ed.), Philosophical Papers (Vol. 1, pp. 39-46). Oxford University Press.

Lewis, D. (1983b). New work for a theory of universals. Australasian Journal of Philosophy, 61(4), 343-377.

Lewis, D. (1986a). On the plurality of worlds. Blackwell.

Lewis, D. (1986b). Philosophical papers (Vol. II). Oxford University Press.

Lewis, D. (1991). Parts of classes. Blackwell.

Lewis, D. (1994). Humean Supervenience debugged. Mind, 103(412), 473-490.

Marshall, D. (2016). A puzzle for modal realism. Philosophers' Imprint, 16(19), 1-24.

Parsons, J. (2012). Against advanced modalizing. In J. Maclaurin (Ed.), Rationis Defensor. Essays in Honour of Colin Cheyne (pp. 139-153). Springer.

Rayo, A., \& Uzquiano, G. (2006). Absolute generality. Oxford University Press.

Roca-Royes, S. (2018). Genuine modal realism, the Humean thesis and advanced modalizing (Synthese). https://doi.org/10.1007/s1122901817285

Williamson, T. (2003). Everything. Philosophical Perspectives, 17(1), 415-465.

Williamson, T. (2010). Necessitism, contingentism, and plural quantification. Mind, 119(475), 657-748.

Williamson, T. (2013). Modal logic as metaphysics. Oxford University Press.

Williamson, T. (2014). Replies to Bricker, Divers, and Sullivan. Philosophy and Phenomenological Research, 88(3), 744-764. 
Zalta, E. N., \& Linsky, B. (1994). In Defense of the Simplest Quantified Modal Logic. Philosophical Perspectives, 8, 431-458.

Zalta, E. N., \& Linsky, B. (1996). In Defense of the Contingently Nonconcrete. Philosophical Studies, $84(2 / 3), 283-294$.

Publisher's Note Springer Nature remains neutral with regard to jurisdictional claims in published maps and institutional affiliations.

This work has not been published elsewhere, nor is it currently under consideration for publication elsewhere. 